Louisiana State University

LSU Digital Commons

$12-1994$

\title{
A Preliminary Mass Balance Model of Primary Productivity and Dissolved Oxygen in the Mississippi River Plume/Inner Gulf Shelf Region
}

Victor J. Bierman Jr.

Scott C. Hinz

William J. Wiseman Jr.

Nancy N. Rabalais

R. Eugene Turner

euturne@lsu.edu

Follow this and additional works at: https://digitalcommons.Isu.edu/oceanography_coastal_pubs

Part of the Oceanography Commons

\section{Recommended Citation}

Bierman, V. J., Hinz, S. C., Wiseman, W. J., Rabalais, N. N., \& Turner, R. (1994). A Preliminary Mass Balance Model of Primary Productivity and Dissolved Oxygen in the Mississippi River Plume/Inner Gulf Shelf Region. Estuaries, 17 (4), 886-889. Retrieved from https://digitalcommons.Isu.edu/ oceanography_coastal_pubs/150 


\title{
A Preliminary Mass Balance Model of
}

\section{Primary Productivity and Dissolved \\ Oxygen in the Mississippi River Plume/ Inner Gulf Shelf Region}

\author{
VICTOR J. BIFRMAN, JR. ${ }^{1}$ \\ Iimno-Tech, Inc. \\ 20780 South Gatehouse Drive \\ South Bend, Indiana 46637 \\ Scott C. Hinz \\ DONG-WEI ZiIU \\ Limno-Tech, Inc. \\ 2395 Huron Parkway \\ Ann Arbor, Michigan 48104
}

WIL IIAM J. WiSEMAN, JR.

Coastal Studies Institute and

Department of Oceanography and Coastal Sciences

Louisiana State University

Baton Rouge, Louisiana 70803

\author{
NANCY N. RABALAIS \\ Iouisiana Universities Marine Consortium \\ 8124 Highway 56 \\ Chauvin, Louisiana 70344 \\ R. Eugrine TLrNer \\ Coastal Ecology Institute and \\ Department of Oceanography and Coastal Sciences \\ Louisiana State University \\ Baton Rouge, Louisiana 70803
}

\begin{abstract}
A deterministic, mass balance model for phytoplankton, nutrients, and dissolved oxygen was applied to the Mississippi River Plume/Inner Gulf Shelf (MRP/IGS) region. The model was calibrated to a comprehensive set of field data collected during July 1990 at over 200 sampling stations in the northern Gulf of Mexico. The spatial domain of the model is represented by a three-dimensional, 21-segment water-column grid extending from the Mississippi River Delta west to the Louisiana-Texas border, and from the shoreline seaward to the $30-60 \mathrm{~m}$ bathymetric contours. Diagnostic analyses and numerical experiments were conducted with the calibrated model to better understand the environmental processes controlling primary productivity and dissolved oxygen dynamics in the MRP/IGS region. Underwater light attenuation appears relatively more important than nutrient limitation in controlling rates of primary productivity. Chemical-biological processes appear relatively more important than advective-dispersive transport processes in controlling bottom-water dissolved oxygen dynamics. Oxidation of carbonaceous material in the water column, phytoplankton respiration, and sediment oxygen demand all appear to contribute significantly to total oxygen depletion rates in bottom waters. The estimated contribution of sediment oxygen demand to total oxygen-depletion rates in bottom waters ranges from $22 \%$ to $30 \%$. Primary productivity appears to be an important source of dissolved oxygen to bottom waters in the region of the Atchafalaya River discharge and further west along the Louisiana Inner Shelf. Dissolved oxygen concentrations appear very sensitive to changes in underwater light attenuation due to strong coupling between dissolved oxygen and primary productivity in bottom waters. The Louisiana Inner Shelf in the area of the Atchafalaya River discharge and further west to the Texas border appears to be characterized by significantly different light attenuation-depth-primary productivity relationships than the area immediately west of the Mississippi Delta. Nutrient remineralization in the water column appears to contribute significantly to maintaining chlorophyll concentrations on the Louisiana Inner Shelf.
\end{abstract}

\section{Introduction}

The Mississippi-Atchafalaya River (MAR) system is the largest single source of freshwater and nuttrient inputs to the coastal waters of the United

\footnotetext{
${ }^{1}$ Corresponding author.
}

States. An extensive and persistent zone of seasonal hypoxia (dissolved oxygen $\leq 2 \mathrm{mg}^{-1}$ ) has been documented in the nearshore bottom waters of the Louisiana-Texas continental shelf (Rabalais et al. 1991, 1992). Turner and Rabalais (1991) speculated that increased nutrient inputs from the MAR system may have affected the extent and severity 
of hypoxia in this region by supporting enhanced levels of primary productivity. Justic et al. (1993) strengthened the evidence for this hypothesis through cross correlation analysis of MAR nutrient inputs, net productivity, and hypoxia in the northern Gulf of Mexico.

The occurrence of hypoxia also depends on certain physical and hydrometeorological factors. Vertical stratification in the water column is generally regarded as a necessary condition for hypoxia (c.g., Swanson and Sindermann 1979; Officer et al. 1984; Turner et al. 1987). Stanley and Nixon (1992) demonstrated that stratification events and bottom-water dissolved-oxygen levels in the Pamlico River Estuary were tightly coupled to variations in freshwater discharge and wind stress. Rabalais et al. (1992) reported that dissipation of summer near-bottom hypoxia on the Louisiana Shelf was event-dominated.

Deterministic mass balance models can be useful tools for synthesizing environmental data and for providing a better understanding of cause-effect mechanisms that lie behind experimental observations. O'Connor (1981) reviewed and evaluated nutrient-phytoplankton models that have been used in water-quality management studies of five different estuaries. Kremer and Nixon (1978) developed a model of phytoplankton, zooplankton, and nutrient dynamics to synthesize a large body of existing information on Narragansett Bay and on marine ecosystems in general. Hoffman (1988) developed a coupled physical-biological model to investigate horizontal fluxes of phytoplankton, carbon, and nitrogen on the southeastern United States continental shelf as a function of upwelling features. Fasham et al. (1990) developed a model for plankton-nitrogen dynamics in the oceanic surface mixed layer and applied it to time series data at a location near Bermuda.

Several of the mass balance modeling studies involving dissolved oxygen in marine systems have been conducted in the New York Bight and in Chesapeake Bay. O'Conner et al. (1981) attempted to disaggregate dissolved oxygen dynamics in the New York Bight 1976 anoxic event (Swanson and Sindermann 1979). Their attempts to investigate the influence of nitrogen loadings from New York Harbor were confounded by lack of information on seaward boundary conditions. Stoddard and Walsh (1988) demonstrated that increased loading of organic carbon could lead to the onset of anoxia within the Bight Apex; however, their analysis did not discriminate between riverine discharges and primary productivity sources. Cerco and Cole (1993) developed and applied a coupled hydrodynamic-water quality model for Chesapeake Bay

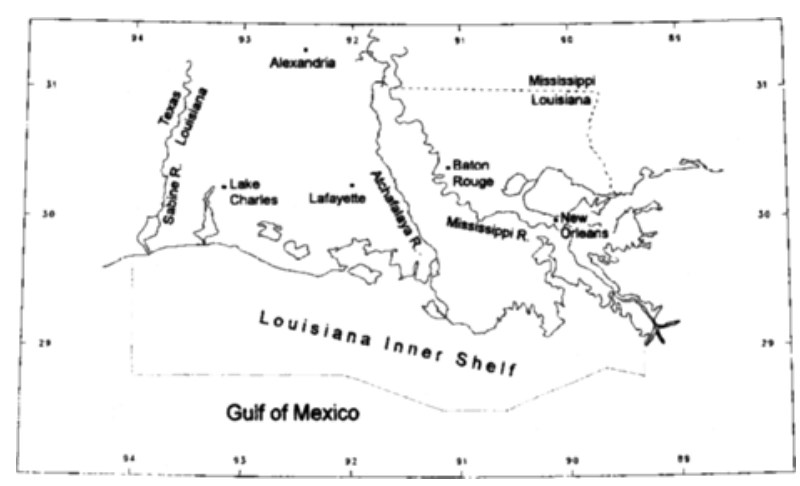

Fig. 1. Map of study area.

that included phytoplankton, nutrients, and dissolved oxygen.

As part of the Nutrient Enhanced Coastal Ocean Productivity (NECOP) program, a study was initiated to synthesize information on physical, chemical, and biological processes in the Mississippi River Plume/Inner Gulf Shelf (MRP/IGS) region within a mass balance modeling framework. This paper contains results from the application of a coarse grid, deterministic model for phytoplankton, nutrients, and dissolved oxygen to the Louisiana Inner Shelf portion of the MRP/IGS region (Fig. 1). The model was calibrated to a comprehensive set of field data collected during July 1990 at over 200 sampling stations in the northern Gulf of Mexico. Diagnostic analyses and numcrical experiments were conducted with the calibrated model to better understand the environmental processes controlling primary productivity and dissolved oxygen dynamics in the study area.

The results presented herein are preliminary because the model has not yet been validated to an independent set of ficld data. Although a previous application of the model was conducted using historical field data for July 1985 (Bierman et al. 1992), these data were not sufficiently comprehensive to adequately constrain model parameters for primary productivity and dissolved oxygen. At the time of this study, field data for July 1990 represcnted the best available dataset for model calibration. It is anticipated that future NECOP datasets will permit independent validation of the model and determination of internally consistent sets of model parameters across different years.

\section{Modeling Approach}

The conceptual framework for the modeling approach is shown in Fig. 2. State variables in the model include salinity, phytoplankton carbon, phosphorus (dissolved phosphate and unavailable forms), nitrogen (ammonia, nitrate plus nitrite, and un- 


\section{Conceptual Framework for Water Quality Model}

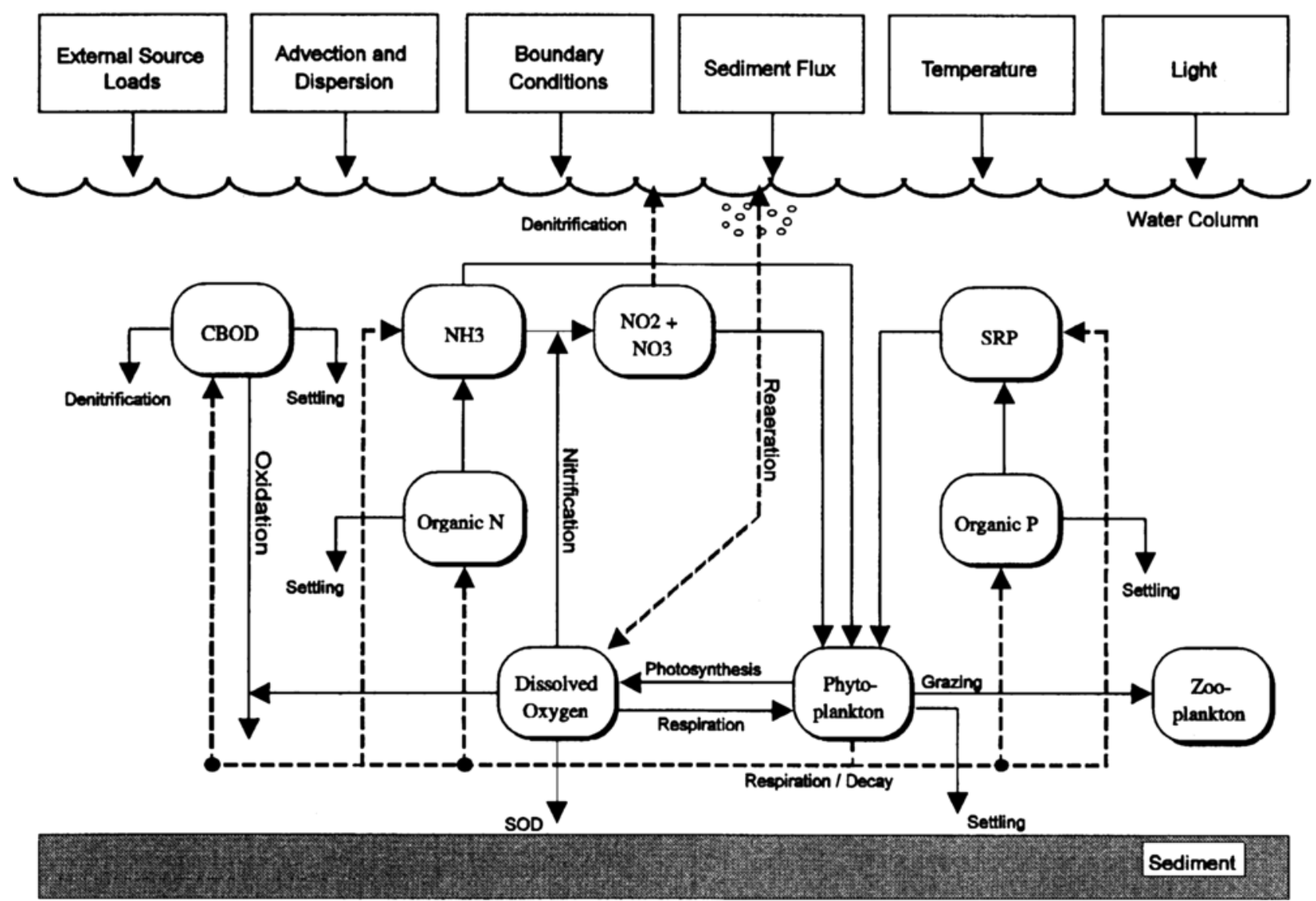

Fig. 2. Schematic diagram of principal model state variables and processes.

available forms), dissolved oxygen, and carbonaccous biochemical oxygen demand. User-specificd external forcing functions include constituent mass loadings, advective-dispersive transport, boundary conditions, sediment fluxes, water temperature, incident solar radiation, and underwater light attenuation. Sediment interactions are represented by user-specified values for net settling rates for particulate phase constituents, sediment-water diffusive fluxes for dissolved nutrients and sediment oxygen dernand. Although this model contains only a moderate degree of chemical-biological complexity it requires a considerable amount of field data for specification of external forcing functions, as well as for comparison with model output.

This model is based on the principle of conservation of mass. For each state variable a partial differential equation is written in which changes in mass are expressed as a function of space and time. Operationally, these equations are solved in the form of a finite difference approximation in which each partial differential equation is transformed to a coupled system of ordinary differential equations, which are a function only of time. The spatial dimension is then represented as a system of coupled segments, or control volumes, within which spatial gradients are assumed to be insignificant. Thomann and Mueller (1987) contains a complete discussion of this control volume approach.

This conceptual model was implemented for the MRP/IGS region using a modified version of the WASP 4 computer coding framework. Ambrose et al. (1988) contains a complete description of WASP4 model theory, governing equations, and a user manual. There were two principal modifications to WASP4 for this application: first, use of a saturation kinetics mechanism for water-column nutrient mineralization proposed by DiToro and Matystik (1979); and second, use of a saturation kinetics mechanism for phytoplankton decomposition proposed by Rodgers and Salisbury (1981). 

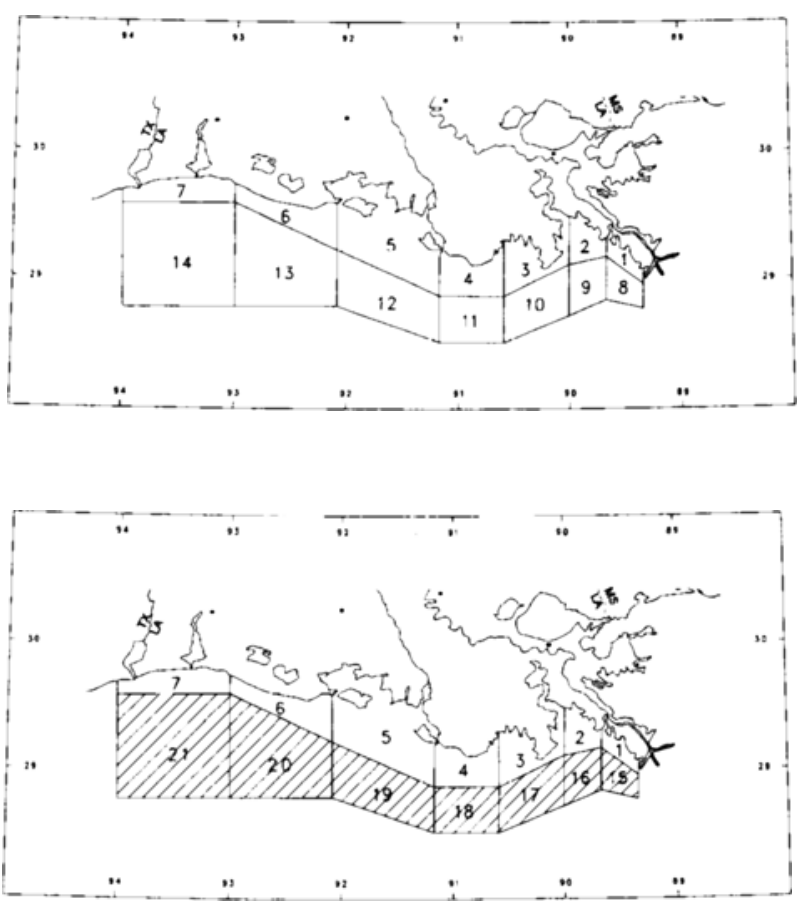

Fig. 3. Model spatial segmentation grid for Mississippi River Plume/Inner Gulf Shelf region. Top panel contains surface segments (segments 1-7 nearshore; segments 8-14 offshore) and bottom panel contains bottom segments (segments 15-21).

\section{Model Application}

\section{SPATIAL AND TrimporAl SCAal.S}

The spatial domain of the model is represented by a 21-segment water-column grid extending from the Mississippi River Delta west to the I LouisianaTexas border, and from the shoreline seaward to the $30-60 \mathrm{~m}$ bathymetric contours (Fig. 3). The spatial segmentation grid includes one vertical layer nearshore and two vertical layers offshore. Consistent with the control volume approach described above, all of the spatial segments are completely mixed. The nearshore segments have an average depth of $5.6 \mathrm{~m}$. The surface offshore segments are completely mixed in the vertical to a fixed pycnocline depth of $10 \mathrm{~m}$. The bottom offshore segments are completely mixed from $10 \mathrm{~m}$ to the seabed. The depths of these bottom offshore segments range between $6.1 \mathrm{~m}$ and $20.3 \mathrm{~m}$ (sec Fig. 10 later in this paper).

The temporal domain of this application represents only steady-state conditions for July 1990. The reason is that time-series data are not available at the shelfwide spatial scale. Typically, a single shelfwide monitoring effort is conducted during the July-August period to characterize the spatial extent of hypoxic conditions in the study area. Operationally, model forcing functions were as-

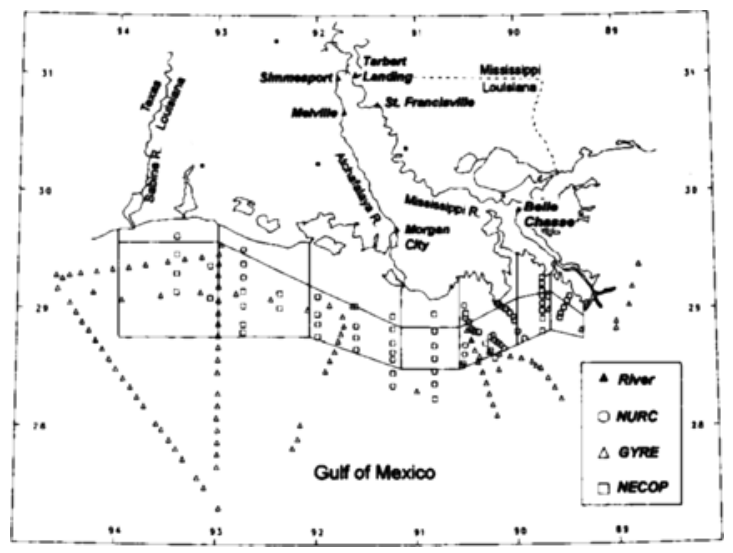

Fig. 4. I ocations of field sampling stations used in model calibration for July 1990 . River $=$ USGS tributary loading stations, NURC $=$ NURC 90 cruise stations, GYRE $=$ GYRE90 cruise stations, NFCOOP $=$ NFCOOP9O shelfwide cruise stations.

signed constant values that represented summer average conditions during 1990. The time-variable model was then run to steady-state, and model output was compared with a combined field dataset from three different sampling cruises conducted during mid-july. It was assumed that these combined data were synoptic and that they were in temporal equilibrium with the specified model forcing functions.

The combined field dataset used for model calibration included the following four groups of sampling stations (Fig. 4): NECOP-NFCOP90 shelfwide cruisc that occupied 64 stations located primarily inside the model segmentation grid; GYRE-GYRE90 cruise conducted by Texas A\&M University that occupied 113 stations located both inside and outside the model segmentation grid; NURC-NLRC90 cruise conducted by Louisiana Universities Marine Consortium, Texas A\&M University at Galveston, and Texas Institute of Oceanography that occupied 38 stations located immcdiately west of the Mississippi Delta in the primary hypoxic region; and River-Cnited States Geological Survey stations in the Mississippi and Atchafalaya rivers. The field data from all of these sampling stations (except river stations) reside in the NECOP database management system and are subject to NECOP policies on quality control, archiving, and distribution (Hendee 1994).

\section{MOdeI. Forcing Functions}

Because the model balances mass and not momentum, magnitudes and directions for advective flows must be externally specified by the user. Water circulation on the Iouisiana-Texas Shelf is strongly influenced by wind stress (Cochrane and Kelly 1986) and freshwater discharges from the 


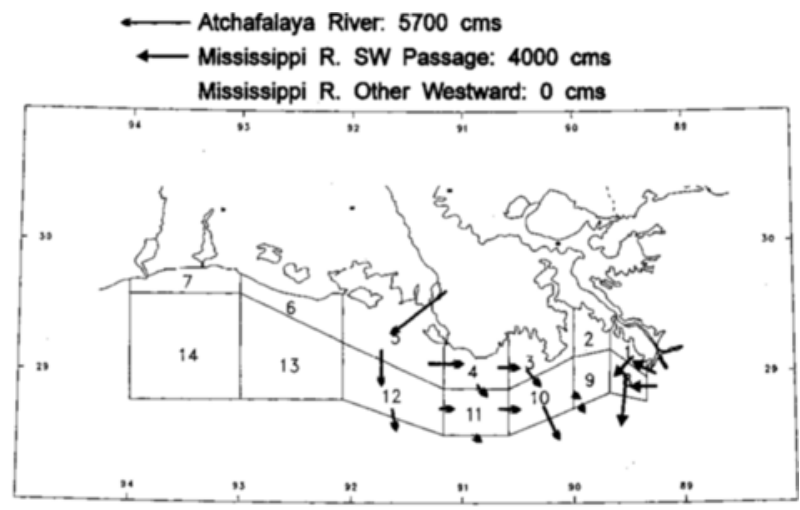

JULY 1990 ADVECTIVE FRESHWATER FLOW DISTRIBUTION

Fig. 5. Schematic diagram of freshwater advective flow fields used in model calibration for July 1990.

Mississippi and Atchafalaya rivers (Wiseman et al. 1982; Dinncl and Wiscman 1986). It is believed that summer average conditions in the spatial domain of the model are typically represented by the Louisiana Coastal Current, which has a net westward drift along the shelf bathymetry. This representation is supported by current meter measurements from a long-term mooring maintained by one of the co-authors (W. J. Wiseman, Jr.) at a location off Cocodrie (segment 10) in $20 \mathrm{~m}$ of water. Typical summer average current speeds are approximately $10 \mathrm{~cm} \mathrm{~s}^{-1}$ and $3 \mathrm{~cm} \mathrm{~s}{ }^{1}$, respectively, in the surface and bottom layers.

Summer 1990 conditions were anomalous in that net eastward drift was observed in both surface and bottom waters at speeds of approximately $2 \mathrm{~cm} \mathrm{~s}^{-1}$ and $0.8 \mathrm{~cm} \mathrm{~s}^{1}$, respectively. The freshwater advective flow fields in Fig. 5 represent our best judgment in synthesizing available data for rivcrine discharges and observed current speeds and directions during July 1990. Values for discharges from the Southwest Pass of the Mississippi River into segments 1 and 8 and from the Atchafalaya River into model segment 5 were based on measurements at Tarbert Landing and Simmesport (Fig. 4), respectively (Lnited States Army Corps of Engineers, New Orleans District Office, personal communication). No freshwater flow from other Mississippi River passages was represented in this application because of the observed net eastward drift in the coastal current. In addition to these freshwater flows, net eastward flow fields of Gulf of Mexico water through the nearshore, surface offshore, and bottom offshore model segments were also represented (not shown). Values for these Gulf of Mexico flows were constrained so that total flow through segment 10 was consistent with current meter observations. The water circulation pat- tern in Fig. $\mathfrak{j}$ is qualitatively consistent with a NOAA-1 1 AVHRR sea surface temperature map for July 25, 1990 (N. D. Walker, Coastal Studies Institute, Iouisiana State University, personal communication).

Mississippi and Atchafalaya river mass loadings for all model state variables were determined using the above riverine discharge values and constituent concentration measurements for June and July 1990 (Cnited States Geological Survey 1991). The principal stations used were the NASQAN stations at Belle Chasse and St. Francisville for the Mississippi River, and at Morgan City and Melville for the Atchafalaya River (Fig. 4). External boundary concentrations for all model state variables were estimated using field data from the above three sampling cruises.

Sediment boundary conditions were specified for nutrient regeneration fluxes and total sediment oxygen demand. Net inorganic nitrogen and phosphate fluxes were taken, respectively, from Rowe et al. (1992) and from other measurements by $G$. T. Rowe (Hendee 1994). The boundary condition for total sediment oxygen demand included aerobic benthic respiration measured using in situ chambers (Rowe et al. 1992) plus an estimate of anaerobic metabolism by G. T. Rowe (Hendec 1994) based on independent measurements of dissolved inorganic carbon fluxes. The anacrobic metabolism component is believed to be mostly sulfate reduction, with subsequent oxidation of the resulting sulfide molecule by dissolved oxygen. There is some question as to whether oxygen consumption measurements in the in situ chambers adequately account for this sulfate reduction component.

Incident solar radiation was taken from direct mcasurements of photosynthetically active radiation by G. L. Fahnensticl (Hendee 1994). Underwater light attenuation was specified using a multiple regression submodel for light extinction coefficient as a function of background attenuation, phytoplankton concentration (as chlorophyll $a)$, and concentration of suspended particulate material (SPM) developed by S. E. Lohrenz (Hendee 1994). SPM concentrations were externally specified using available field data from IIendee (1994). Phytoplankton concentrations were computed internally by the mass balance model, thus explicitly accounting for variations in underwater light attenuation due to phytoplankton "self-shading". Water temperatures were specified using direct ficld observations from the sampling cruises.

\section{Modei. Calibration}

The calibration approach was to fix the values of as many model coefficients as possible based on direct measurements. Subsequently, values for the 

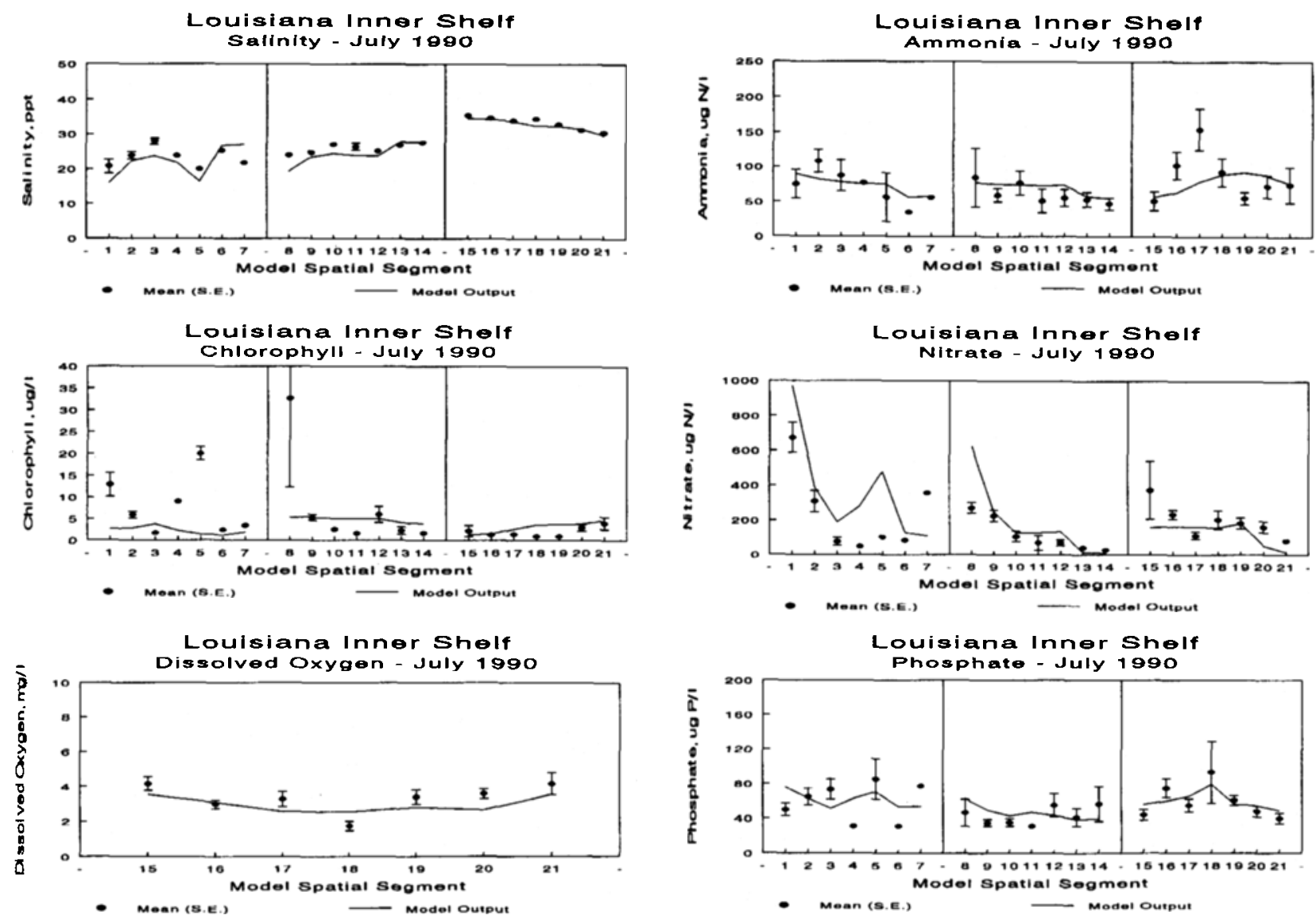

Fig. 6. Relationship between model output and field data for salinity (top panel), chlorophyll $a$ concentration (middle panel), and dissolved oxygen concentration (bottom panel) in model calibration for July 1990.

remaining coefficients were adjusted within ranges from the scientific literature to produce the best fit between model output and field observations. Model coefficients were not allowed to assume arbitrary values in order to obtain the best possible curve fits in a strictly mathematical sense. In particular, a unified set of model process rates and stoichiometric coefficients was assigned across all 21 spatial segments. The principal literature sources and data compendia used to guide the calibration effort were Bowic et al. (1985), Thomann and Mueller (1987), Ambrose et al. (1988), and Jorgensen et al. (1991).

Model calibration results for salinity, chlorophyll, dissolved oxygen, and nutrients are shown in Figs. 6 and 7. All field data are represented as the spatial segment mean $\pm 1 \mathrm{SE}$ of the mean. Model output is represented as a solid line. With the cxception of dissolved oxygen, results are presented in terms of three vertical panels: left panel-nearshore segments (1-7); middle panel-surface off-

Fig. 7. Relationship between model output and field data for ammonia nitrogen concentration (top panel), nitrate plus nitrite nitrogen concentration (middle panel), and phosphate phosphorus concentration (bottom panel) in modcl calibration for July 1990.

shore segments (8-14); and right panel-bottom offshore segments (15-21). Model results for dissolved oxygen are presented only for bottom offshore segments (15-21) because results for surface segments (1-14) are all close to saturation values, as expected and observed.

The first step in model calibration was to determine dispersive mixing coefficients across all horizontal and vertical interfaces. This was accomplished by conducting a mass balance for salinity, a conservative tracer. Results indicate reasonably good agreement between model output and field observations (Fig. 6, top panel). Model calibration for segments $1-7$ was confounded by the fact that sampling vessels could not occupy locations with water depths less than $5 \mathrm{~m}$. In particular, the potential influence of Atchafalaya River discharge on segments 4-6 was not well-captured by the sampling program (Fig. 4). Consequently, field observations for these segments do not necessarily represent true segment-average conditions. For this 
reason, greater emphasis should be placed on offshore segments $(8-21)$ than on nearshore segments $(1-7)$ in evaluating model calibration results. It should be understood that although model results cannot be compared with representative field data in all model spatial segments, the model equations are inherently mass-conserving and they constrain cxternal inputs with constituent transport, transformation and fate simultancously among all spatial segments.

Model calibration results for phytoplankton are displayed in terms of chlorophyll a concentration (Fig. 6, middle panel). Internally the model computes phytoplankton biomass in terms of organic carbon. A carbon:chlorophyll ratio is then assigned solely for the purpose of comparing model output with field observations. A complication is that this ratio varies by an order of magnitude (12125) within the study area (Lohrenz et al. 1992). Observations by D. G. Redalje (Hendee 1994) indicate that values lic at the low end of this range at plume stations and at higher values at inner shelf stations. A carbon : chlorophyll ratio of 50 was used in the model calibration.

There is reasonable agreement betwcen model output and field observations for chlorophyll concentration except for segments 1,5 , and 8 in which observations are much larger than model output. A confounding factor in segments 1,5 , and 8 is that water quality in these scgments closely resembles plume conditions due to direct discharges from the Mississippi and Atchafalaya rivers. Model output for chlorophyll concentration in these segments deviates from field observations both in the expected direction and by approximately the expected magnitude, given the extremely low values for carbon: chlorophyll ratio under plume conditions. Although a carbon : chlorophyll ratio of less than 50 would have improved chlorophyll calibration results in segments 1,5 , and 8 , results in most of the other segments would have been poorer. Consistent with the objective of assigning an internally consistent set of model coefficients across all 21 spatial segments, a carbon : chlorophyll ratio of 50 was judged to produce the best overall calibration results.

Model output for dissolved oxygen in bottom offshore segments (Fig. 6, bottom panel) agrees reasonably well with field observations. Oxygen concentrations range from $3 \mathrm{mg} \mathrm{l}^{-1}$ to $5 \mathrm{mg} \mathrm{l}^{1}$ below saturation values at ambient temperatures and salinities. Model output for nutrient concentrations (Fig. 7) agrees reasonably well with field observations, especially for surface and bottom offshore segments. The most serious discrepancies occur for nitrate plus nitrite concentrations in some nearshore and plume-dominated segments. In ad-
TABIE. 1. Comparison betwecn model calibration results and observations in primary hypoxic region (model segments 10 and 17) for July 1990.

\begin{tabular}{|c|c|c|}
\hline Parameter & $\begin{array}{l}\text { Observed } \\
\text { Mean (SE) }\end{array}$ & $\begin{array}{l}\text { Model } \\
\text { Result }\end{array}$ \\
\hline Primary Productivity, $\mathrm{mg} \mathrm{C}^{-1} \mathrm{~d}^{1}$ & $0.31(0.08)^{\mathrm{a}}$ & 0.30 \\
\hline Integrated Primary Prod, $\mathrm{mg} \mathrm{C} \mathrm{m}^{-2} \mathrm{~d}^{1}$ & $3734(213)^{b}$ & 3943 \\
\hline POC Secting Flux, g $\mathrm{C} \mathrm{m}^{-2} \mathrm{~d}^{1}$ & $0.18(0.007)^{c}$ & 0.16 \\
\hline PON Settling Flux, g $\mathrm{N} \mathrm{m}^{2} \mathrm{~d}^{-1}$ & $0.03(0.002)^{\mathrm{c}}$ & 0.03 \\
\hline Algal Biomass, $\operatorname{mg} \mathrm{C}^{-1}$ & $0.48(0.10)^{\mathrm{a}}$ & 0.25 \\
\hline DOC, $\operatorname{mg~I^{-1}}$ & $2.03(0.24)^{d}$ & 2.22 \\
\hline $\mathrm{DON}, \mathrm{mg} \mathrm{l}^{-1}$ & $0.37(0.05)^{c}$ & 0.30 \\
\hline
\end{tabular}

a Lohrenz et al. 1992

b Lohrenz et al. 1992; G. I. Fahnenstiel (in Hendee 1994)

c Redalje et al. 1992

"Benner et al. 1992

c Lopez-Veneroni et al. 1992

dition to the nearshore sampling problem discussed above, other possible causes for these discrepancies might be unaccounted localized sources or temporal variability not represented by this steady-state application.

Although comparisons between computed and observed values for model state variables are necessary for establishing model credibility, considerable uncertainties may remain because it is usually not possible to determine unique sets of model calibration coefficients. Comparisons between computed and observed values for model process rates and mass fluxes can greatly narrow these uncertainties and enhance the scientific credibility of the model. Table 1 contains such comparisons for various process rates and mass fluxes, and for phytoplankton carbon, dissolved organic carbon, and dissolved organic nitrogen from specialized measurements conducted in the primary hypoxic rcgion (segments 10 and 17).

Model output for volumetric and integrated primary productivity agree extremely well with field obscrvations. This confirms that the model is accurately representing production of new organic carbon in the water column. Model output for POC and PON settling fluxes also agrees very well with ficld observations. This confirms that the model is accurately representing the proportions of newly produced organic material that remain in the surface mixed layer or settle to the bottom waters. Although observations for dissolved oxygen depletion rates in the water column are not available for July 1990, the value from the model calibration $\left(0.22 \mathrm{mg} \mathrm{O}_{2} \mathrm{I}^{1} \mathrm{~d}^{-1}\right.$ agrees well with rates reported in the literature from a large number of marine systems (Table 2, Dortch et al. 1992b).

Model output for DON concentration agrees well with field observations. In conjunction with calibration results for ammonia and nitrate plus nitrite concentrations in segment 10 (Fig. 7, top 


\section{Louisiana Inner Shelf Phyto Growth Rate Components - July 1990}

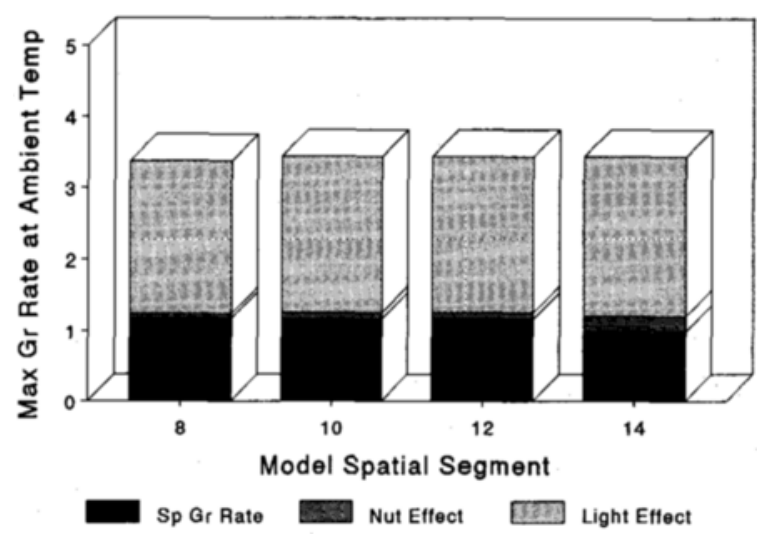

Fig. 8. Component analysis of phytoplankton growth rates in the calibrated model as a function of temperature, light, and nutrient limitations of selected surface offshore segments. Sp Gr Rate = resultant specific growth rate, Nut Effect $=$ reduction due to nutrient limitation, I ight Effect = reduction due to light limitation.

and middle panels), this confirms that the model accurately represents total nitrogen in the water column. Good agreement is also obtained between computed and observed dissolved organic carbon concentrations. Finally, model output for phytoplankton biomass in terms of carbon concentration is lower than field observations. It is important to note that model output for phytoplankton biomass in terms of chlorophyll concentration is higher than field observations in this same region (segment 10) (Fig. 6, middle panel). These offsetting discrepancies reflect the difficulties caused by using two different parameters as indicators of phytoplankton biomass, and the uncertainties in specification of a carbon: chlorophyll ratio.

\section{Diagnostic and Sensitivity Analyses \\ PifyiopiankTON GROWTH RATE COMPONENTS}

An important question in the NECOP program concerns the relative importance of environmental factors controlling primary productivity. Under conditions of optimal temperature, light, and nutrients, phytoplankton growth rates are limited solely by physiology. Under ambient conditions water temperature generally determines upper bound maximum growth rates. Specific growth rates actually realized depend on potential limiting effects due to underwater light attenuation and nutrient limitation.

The components of phytoplankton growth rates in the calibrated model due to temperature, light, and nutrient effects are shown in Fig. 8 for four representative surface offshore model segments.
All rates shown represent vertical averages in the 10-m decp surface mixed layer. Maximum growth rates at ambient temperatures are high (approximately $3.0 \mathrm{~d}^{-1}$ ) due to high summer water temperatures in the Gulf of Mexico. Growth rate limitation due to underwater light attenuation is substantially greater than growth rate limitation due to nonoptimal nutrient concentrations. Actual specific growth rates decrease and the degree of nutrient limitation increases with increasing distance from the Mississippi Delta. Specific growth rates remain relatively high in all segments, ranging between $1.0 \mathrm{~d}^{-1}$ and $1.2 \mathrm{~d}^{-1}$. These values are consistent with taxon-specific growth rates estimated from ${ }^{14} \mathrm{C}$-autoradiography experiments conducted in the plume and primary hypoxic regions (segments 8, 9, and 10) (Fahnenstiel et al. 1992).

\section{ANalysis of Dissol.yed OXYgren Dynamics}

Another important question in the NECOP program concerns the principal factors controlling dissolved oxygen and seasonal hypoxia on the Louisiana Inner Shelf. The total mass balance components of dissolved oxygen are shown in Fig. 9 (top panel) for four representative bottom offshore model segments. The magnitudes of chemical-biological processes (photosynthesis and depletion) are greater than those of advective-dispersive transport processes in all four segments. Photosynthesis is the largest source of dissolved oxygen, and depletion (water column plus sediment demand) is the largest sink of dissolved oxygen in all four segments. Furthermore, the magnitudes of these two processes increase with increasing distance from the Mississippi Delta.

Individual components of total oxygen depletion rates for these same four model segments are shown in the bottom panel of Fig. 9. Oxidation of carbonaceous material in the water column (CBOD), phytoplankton respiration, and sediment oxygen demand (SOD) all contribute significantly to total oxygen depletion rates. CBOD is the largest component in each of the four segments, and its relative contribution increases with increasing distance from the delta. Nitrification is a relatively small component in all four segments. The computed contribution of sediment oxygen demand to total oxygen depletion rates ranges from $22 \%$ to $30 \%$.

It is not intuitively clear why photosynthesis should be a source of dissolved oxygen in bottom offshore waters, nor is it clear why this source should become progressively larger with increasing distance from the delta (Fig. 9, top panel). A components analysis of phytoplankton growth rates in these bottom segments (Fig. 10) indicates that changes in water-column depth are partly respon- 


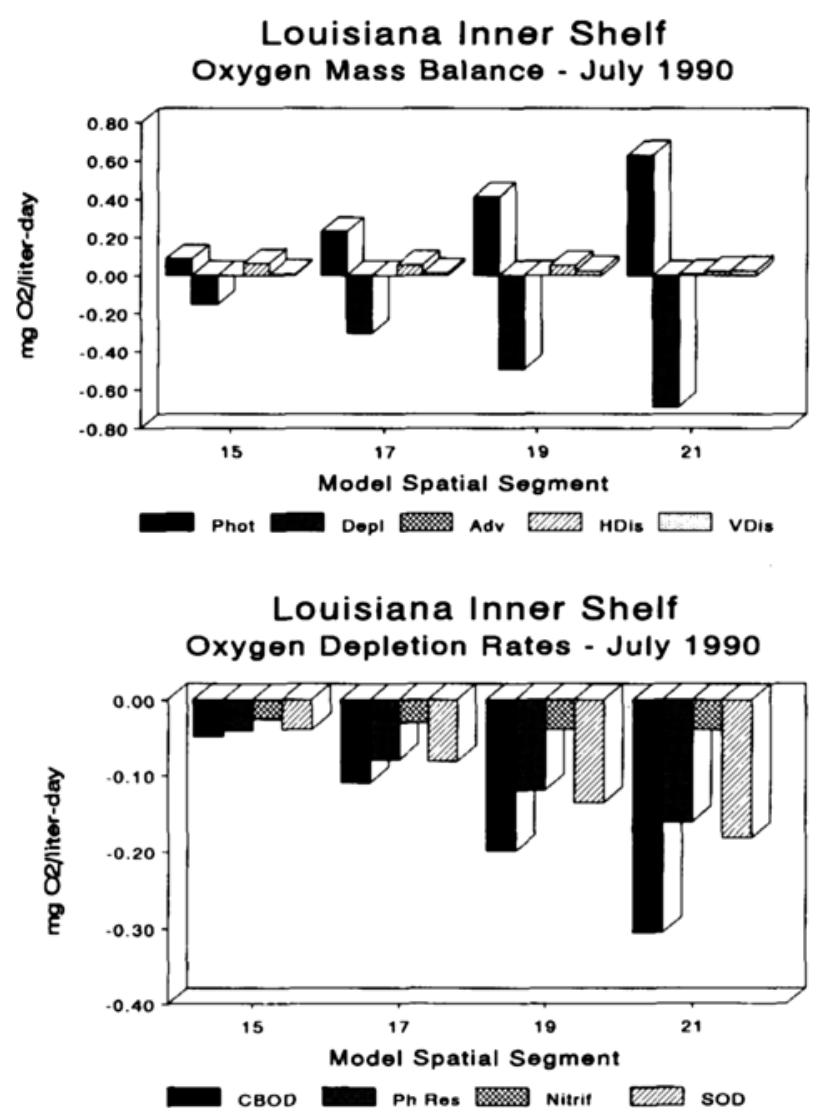

Fig. 9. Component analysis of dissolved oxygen sources and sinks in the calibrated model for selected bottom (offshore) segmients. 'Total mass balance components (top panel): Phot $=$ photosynthesis, Depl = depletion due to water column processes plus sediment oxygen demand, Adv $=$ net advective exchange, HDis $=$ net horizontal dispersive exchange, VDis $=$ net vertical dispersive exchange. Depletion rate components (bottom panel): $\mathrm{CBOD}=$ carbonaceous biochemical oxygen demand in the water column, Ph Res =: phytoplankton respiration, Nitrif $=$ nitrification, SOI $=$ sediment oxygen demand (areal rate expressed as a volumetric demand).

sible for this phenomenon. Maximum growth rates increase with increasing distance from the delta due to higher water temperatures. More importantly, growth rate limitation due to underwater light attenuation becomes relatively less important with increasing distance from the delta due to a decrease in water-column depth from $20.3 \mathrm{~m}$ (segment 15) to $6.1 \mathrm{~m}$ (segment 21). In spite of a small increase in the degree of nutrient limitation, actual specific growth rates increase from $0.44 \mathrm{~d}^{1}$ in segment 15 to $0.99 \mathrm{~d}^{1}$ in segment 21 .

The importance of light attenuation-depth relationships in the calibrated model is illustrated in Fig. 11. The indicated light saturation depth is the balance point between phytoplankton growth rate limitation by photoinhibition (above saturation depth) and growth rate limitation by suboptimal

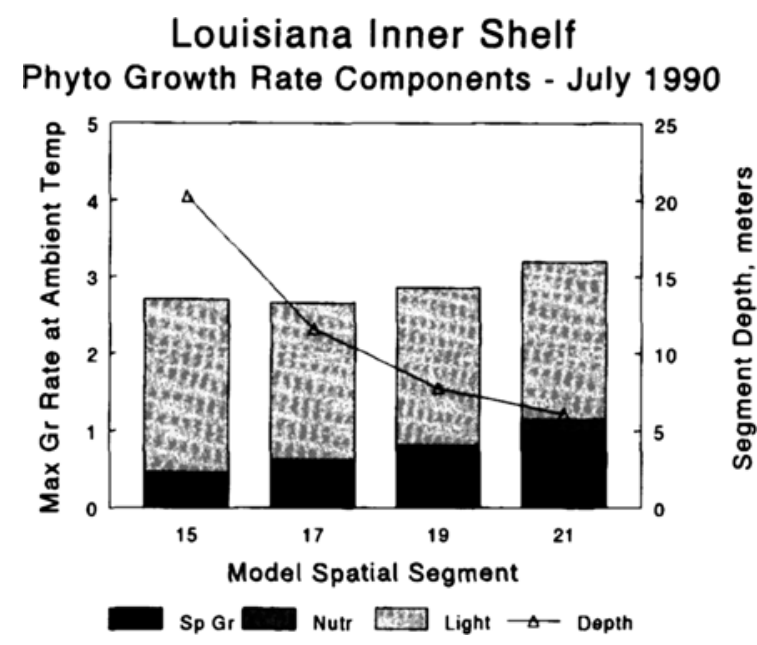

Fig. 10. Component analysis of phytoplankton growth rates in the calibrated model as a function of temperature, light, and nutrient limitations, and model segment depth. Selected bottom (offshore) segments; Sp Gr Rate = resultant specific growth rate, Nutr $=$ reduction due to nutrient limitation, Light $=$ reduction due to light limitation, Depth = model segment depth.

light intensity (below saturation depth). Phytoplankton growth rate in the model increases as a function of increasing light intensity up to a saturating level and then decreases (photoinhibition) with further increases in light intensity (Thomann and Mucller 1987). The values for incident solar radiation and saturating light intensity in the calibrated model are 400$)^{\text {ly d }}{ }^{1}\left(891 \mu \mathrm{E} \mathrm{m}^{-2} \mathrm{~s}^{1}\right)$ and $125 \mathrm{ly} \mathrm{d}^{1}\left(278 \mu \mathrm{E} \mathrm{m}^{-2} \mathrm{~s}^{-1}\right)$, respectively. The theoretical $1 \%$ depth, as estimated from light extinction coefficients in the calibrated model, is the

\section{Louisiana Inner Shelf} Light Attenuation - July 1990

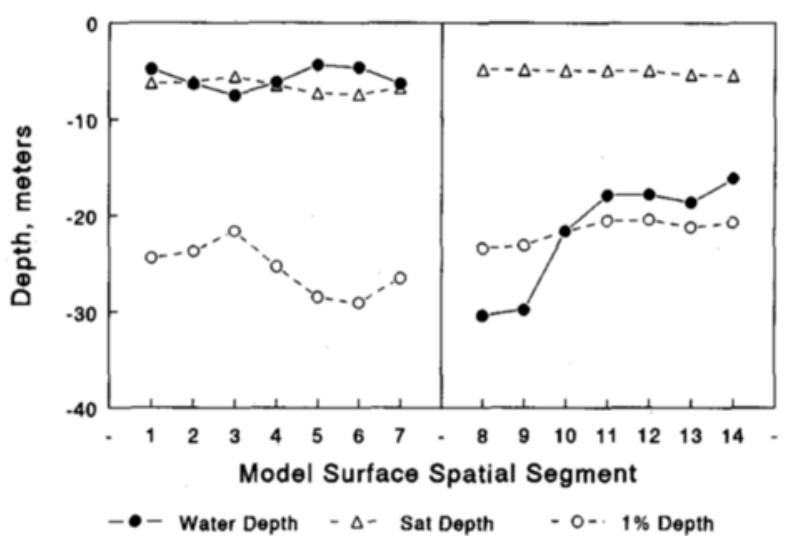

Fig. 11. Relationships among total water-column depth (Water Depth), phytoplankton light-saturation depth (Sat Depth), and theoretical $1 \%$ light-attenuation depth (1\% Depth) as estimated from light extinction coefficients in the calibrated model. 


\section{Louisiana Inner Shelf} Dissolved Oxygen Sensitivity - July 1990

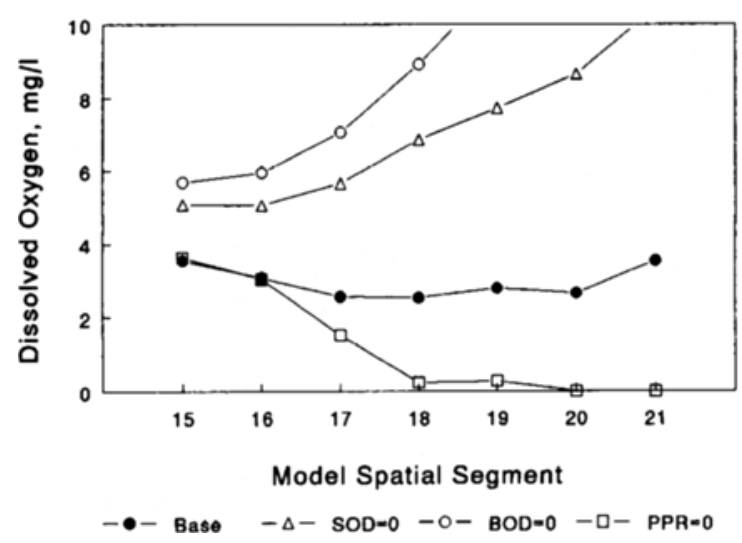

Fig. 12. Responses of dissolved oxygen concentration, relative to base calibration values, to imposition of zero values for sediment oxygen demand (SOD), oxidation of carbonaceous material in the water column (BOD), and primary productivity (PPR) in bottom (offshore) segments.

compensation depth at which photosynthetic oxygen production approximately balances oxygen consumption due to endogenous respiration.

Below segments 11-14, west of the primary hypoxic region, the theoretical $1 \%$ depth is greater than the total depth of the water column. This implies that phytoplankton are a net source of dissolved oxygen in this region. This model result is consistent with independent observations confirming that considerable primary production occurs on the sediment surface in the model spatial domain, especially further west along the inner shelf. For 12 locations at which measurements were conducted, G. T. Rowe (Hendee 1994) has reported that bottom productivity rates averaged approximately $30 \%$ of water-column productivity rates.

To further illustrate the relative importance of factors controlling dissolved oxygen concentrations, three numerical experiments were conducted with the calibrated model. Zero values were imposed, in turn, on SOD, CBOD, and primary productivity. Figurc 12 contains results from these experiments relative to base calibration values. Consistent with results in the bottom panel of Fig. 9 , increases in dissolved oxygen concentration are greater in response to "turning off" CBOD than to "turning off" SOD. Consistent with the above analysis, dissolved oxygen concentrations in segments 18-21 decrease sharply in response to "turning off" primary productivity. There is no signifcant change in dissolved oxygen concentrations in segments 15 and 16 near the delta because photosynthesis in these segments is relatively small.
Louisiana Inner Shelf Chlorophyll Sensitivity - July 1990

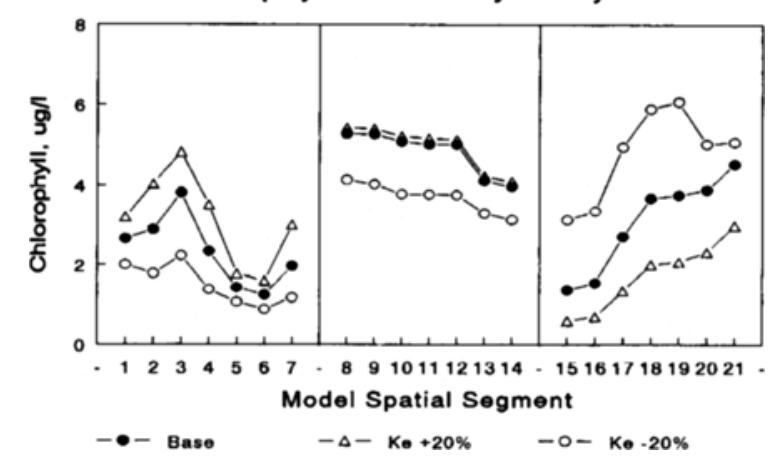

Louisiana Inner Shelf Dissolved Oxygen Sensitivity - July 1990

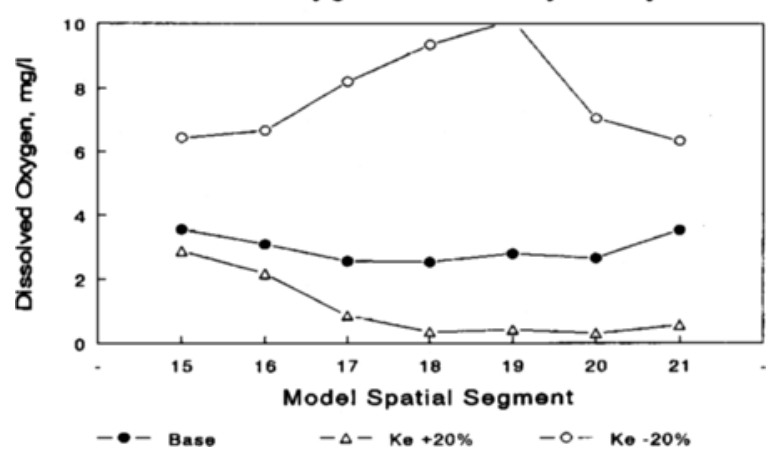

Fig. 13. Response of chlorophyll a concentration (top panel, all segments) and dissolved oxygen concentration (bottom pan$\mathrm{el}$, bottom offshore segments) to $\pm 20 \%$ changes in underwater light attenuation coefficient (Ke).

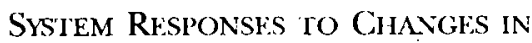 UNDDERWATER LIGIT ATTENUATION}

To illustrate the strong coupling between the underwater light field and chlorophyll and dissolved oxygen concentrations, a numerical experiment was conducted with the calibrated model in which the underwater light attenuation coefficient (Ke) was varied by $\pm 20 \%$. This experiment is more realistic than simply "turning off" individual processes because there is considerable experimental uncertainty in determining values for underwater light attenuation coefficients. The responses of chlorophyll concentrations (Fig. 13, top panel) are completely consistent with the light attenuationdepth relationships in Fig. 11. In the bottom waters (segments 15-21), chlorophyll concentrations increase in response to decreased light attenuation (Ke minus 20\%) and decrease in response to increased light attenuation (Kc plus 20\%).

The chlorophyll concentration responses in the surface waters (segments 1-14) are the complete inverse of responses in the bottom waters and 
these responses appear to be counterintuitive. From Fig. 11, however, it can be seen that the light saturation depth is approximately 5-7 $\mathrm{m}$. This implies that phytoplankton growth rates are limited by photoinhibition in nearshore waters (segments 1-7) and in major portions of the surface offshore waters (scgments 8-14). Consequently, chlorophyll concentrations increase in response to increased light attenuation ( $\mathrm{Ke}$ plus 20\%), especially in the nearshore waters, and decrease in response to decreased light attenuation (Ke minus $20 \%$ ).

The responses of dissolved oxygen concentrations in bottom waters (segments 15-21) (Fig. 13, bottom panel) are consistent with the corresponding responses of chlorophyll concentrations. Because dissolved oxygen concentrations in these segments are strongly coupled to primary productivity, oxygen concentrations increase substantially in response to increased chlorophyll concentrations, and decrease sharply in response to decreases in chlorophyll concentrations. Consistent with results in Fig. 12, oxygen concentrations decrease more sharply in segments 18-21, west of the primary hypoxic region (segments 10 and 17).

\section{SYSTEM RESPONSES TO CHANGES IN NUTRIENT REMINERALIZATION}

Another important question in the NECOP program concerns the relative importance of "new" versus "regenerated" nutrients in driving primary productivity. In this context "new" nutrients refers to external loadings from riverine sources and "regenerated" nutrients refers to nutrients that are recycled within the water column. To address this question a numerical experiment was conducted with the calibrated model in which zero values were imposed on water-column remineralization of both nitrogen and phosphorus. A sccond experiment was conducted in which zero values were imposed on nitrogen and phosphorus fluxes from the sediments.

In response to "turning off" water-column nutrient remineralization, chlorophyll concentrations decreasc substantially in almost all model segments (Fig. 14, top panel). The smallest chlorophyll responses occur in segments 15 and 16 because these are the deepest and most light-limited of all the model segments (Fig. 11). Responses to "turning off" sediment nutrient fluxes are insignificant because these loading sources are small relative to MAR mass loadings. Furthermore, sediment nutrient loadings are prevented from impacting surface offshore segments during the summer stratified period.

Consistent with results in Fig. 13, dissolved oxygen concentrations in bottom waters (segments 15-21) are responsive to decreases in chlorophyll
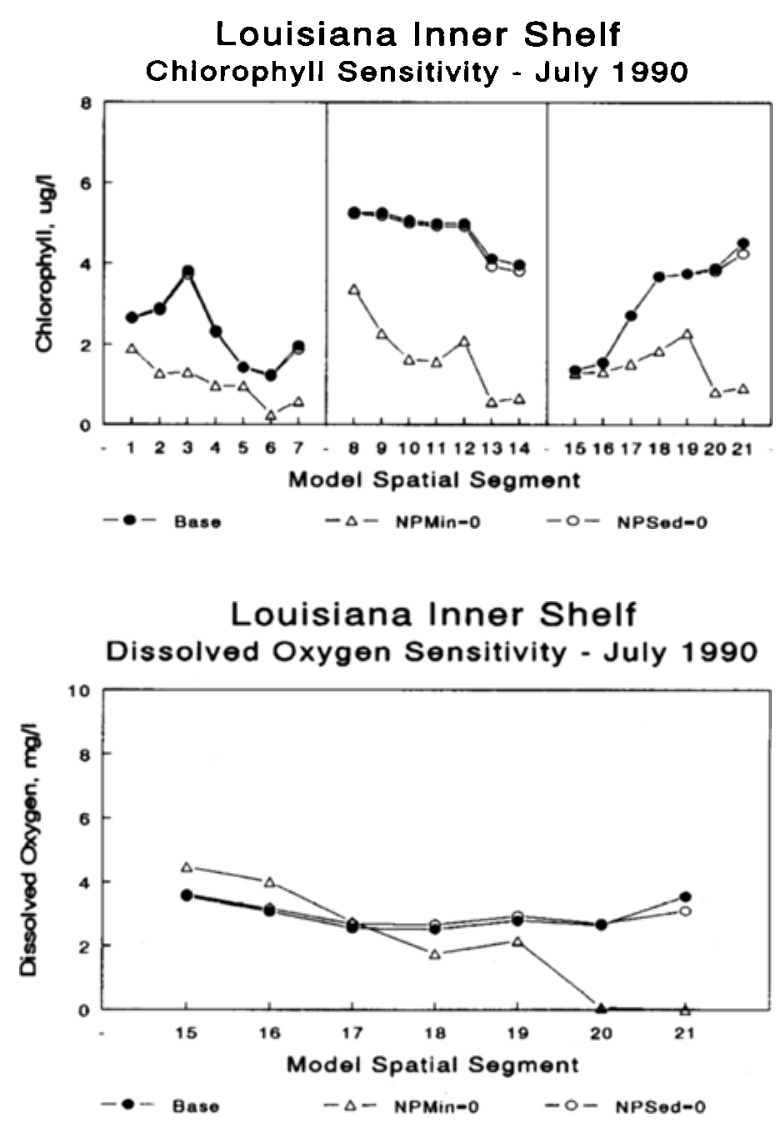

Fig. 14. Responses of chlorophyll a concentration (top panel, all segments) and dissolved oxygen concentration (bottom panel, bottom offshore segments) to imposition of zero values for nitrogen and phosphorus mincralization rates ( NPMin $=0$ ) and sediment fluxes (NPSed $=0$ ).

concentrations. In contrast to the results in Fig. 13, however, the present decreases in dissolved oxygen concentration in segments 18-21 west of the primary hypoxic region are smaller. In addition, dissolved oxygen concentrations now increase somewhat in segments 15 and 16 near the delta. The reason is that in the present experiments, "turning off" nutrient remineralization not only decreases chlorophyll concentrations, but also decreases ammonia nitrogen concentrations. In turn, oxygen depletion rates decrease because of decreased nitrification. In segments 15 and 16 , gains in oxygen due to decreased nitrification are somewhat greater than losses in oxygen due to the relatively small changes in chlorophyll concentrations. These results illustrate the complex interactions among phytoplankton, nutrient, and dissolved oxygen dynamics in the study region.

\section{Discussion}

In assessing the significance of results from the component analyses of phytoplankton growth rates 
(Figs. 8 and 10), a distinction should be made between rate limitation and stoichiometric limitation. The former refers to limitation of specific growth rates, while the latter refers to limitation of the amount of phytoplankton biomass that can be produced. The results in Figs. 8 and 10 indicate that light effects are more important than nutrient effects in controlling phytoplankton growth rates. It does not follow, however, that reductions in riverine nutrient loadings and/or nutrient boundary conditions will not significantly affect phytoplankton concentrations. The reason is that phytoplankton growth rates can only be maintainced if there are adequate nutricnt supply rates.

Although model responses to changes in external nutrient loadings and/or nutrient boundary conditions were not investigated in this study, responses to changes in nutrient supply rates can be seen in results from the remineralization experiment. For example, when internal nutrient supply rates were "turned off", chlorophyll concentrations decreased substantially (Fig. 14, top panel). This implies that primary productivity, and possibly dissolved oxygen, in the MRP/IGS region may be responsive to changes in external nutrient inputs.

The result that chemical-biological processes are relatively more important than advective-dispersive transport processes in controlling dissolved oxygen (Fig. 9, top panel) should be interpreted within the spatial-temporal scales of this model application. All results in this paper represent the coarse spatial scale of the model segmentation grid and summer average steady-state conditions. Potential responses of dissolved oxygen concentrations to meteorological events, shelf-edge upwellings, and mesoscale shelf circulation are not represented.

The result that sediment oxygen demand accounts for $22 \%$ to $30 \%$ of total oxygen demand is remarkably consistent with results for Chesapeake Bay and Lake Erie. Kemp et al. (1992) measured benthic and planktonic oxygen consumption, planktonic oxygen production, and changes in surface and bottom dissolved oxygen pools at two mesohaline sites in Chesapeake Bay that cxpcricnce seasonal hypoxia. The water column depths at these two stations were $9 \mathrm{~m}$ and $18 \mathrm{~m}$. They found that benthic processes accounted for approximately one-third of the total oxygen demand. DiToro et al. (1987) conducted a long-term mass balance modcling study of phytoplankton, nutrients, and dissolved oxygen in I ake Erie, which experiences seasonal hypoxia in the Central Basin (mean depth $24 \mathrm{~m}$ ). They concluded that sediment oxygen demand accounts for approximately $30 \%$ to $40 \%$ of the total oxygen demand, depending on the annual climatic conditions and seasonal thermocline structure.
Results presented in Figs. 10,11, and 12 suggest that the Louisiana Inner Shelf in the area of the Atchafalaya River discharge and further west to the Texas border is characterized by significantly different light attenuation-depth-primary productivity relationships than the area immediately west of the Mississippi Delta. In particular, dissolved oxygen dynamics appear much more strongly coupled to primary productivity with increasing distance from the delta. This phenomenon does not appear to be mediated by along-shelf transport of Mississippi River discharge, at least under the present model calibration conditions, because net advective flows are in the castward direction (Fig. 5). It should be noted again that the typical behavior of the I ouisiana Coastal Current is believed to be represented by net westward flows, and that summer conditions during 1990 are considered to be anomalous.

The sensitivity of both chlorophyll and dissolved oxygen concentrations to relatively small changes in the underwater light field (Fig. 13) emphasizes the importance of adequate measurements of attenuation coefficients for downwelling irradiance and correlated parameters. These correlated parameters should include chlorophyll and SPM concentrations, Secchi disk depth, beam attenuation coefficient, and salinity. It is not sufficient to measure underwater light attenuation coefficients and specify these values directly to the mass balance model. If this were done, the model would only be valid for the particular conditions under which the attenuation coefficients were measured. Such a model would not be valid for conducting any sensitivity or predictive analyses that involved changes in chlorophyll concentration or any other parameters that co-vary with light attenuation coefficient. A credible and useful mass balance model requires an independent submodel for underwater light attenuation as a function of chlorophyll concentration and any other significantly correlated parameters.

Dortch et al. (1992a) have hypothesized that the high productivity observed on the I ouisiana Shelf is maintained by nitrogen recycling within the water column, thus greatly amplifying the effect of high riverine nitrate inputs. Although results in Fig. 14 represent a numerical experiment in which both nitrogen and phosphorus remineralization rates were "turned off", the substantial decrease in chlorophyll concentration is consistent with this hypothesis. This hypothesis is further supportcd by the result (not shown) that primary productivity in the calibrated model is relatively more controlled by nitrogen than by phosphorus in the primary hypoxic region (scgments 10 and 17) and further west along the Louisiana Shelf. It should be noted, however, that primary productivity in the model is 
more controlled by phosphorous than by nitrogen in the region immediately west of the Mississippi Delta (segments 8 and 9), consistent with experimental observations by Ammerman (1992).

\section{Conclusions}

The following conclusions are drawn from this preliminary modeling study of primary productivity and dissolved oxygen in the MRP/IGS region. A reasonable model calibration has bcen obtained for summer average conditions as represented by available shelfwide ficld data for July 1990 . Underwater light attenuation appears relatively more important than nutrient limitation in controlling rates of primary productivity in the study area. Chemical-biological processes appear relatively more important than advective-dispersive transport processes in controlling bottom-water dissolved oxygen dynamics. Oxidation of carbonaceous material in the water column, phytoplankton respiration, and scdiment oxygen demand all appear to contribute significantly to total oxygen depletion rates in bottom waters. The estimated contribution of sediment oxygen demand to total oxygen depletion rates in bottom waters ranges from $22 \%$ to $30 \%$. Primary productivity appears to be an important source of dissolved oxygen to bottom waters in the region of the Atchafalaya River discharge and further west along the L ouisiana Inner Shelf. Dissolved oxygen concentrations appear very sensitive to changes in underwater light attenuation due to strong coupling between dissolved oxygen and primary productivity in bottom waters. The Louisiana Inner Shelf in the area of the Atchafalaya River discharge and further west to the Texas border appears to be characterized by significantly different light attenuation-depth-primary productivity relationships than the area immediately west of the Mississippi Delta, and Nutrient remineralization in the water column appears to contribute significantly to maintaining chlorophyll concentrations on the Louisiana Inner Shelf.

These conclusions should be considered preliminary because the model has not yet been validated to an independent set of field data. It should also be noted that the typical behavior of the Louisiana Coastal Current is believed to be represented by net westward flows, and that flow conditions for the present model application are considered to be anomalous. Future work in this NECOP modeling study will include application of the steadystate model to summer average conditions for different years, and application of a time-variable version of the model to field data from six different surveys representing spring and summer conditions in 1993.

\section{ACKNOWLEDGMENTS}

This modeling research was supported by the NOAA Coastal Ocean Program Office through grant no. NA90AA-D-SG691 to the Louisiana State University Sea Grant Program. Support to limno-Tech, Inc. was provided through subcontract no. R136643 from Louisiana State Lniversity. NECOP90 (July 1990) shelfwide survey data were acquired with support from Louisiana Board of Regents Education Quality Support Fund grant no. L.EQSF (1987-90)-RD-A-15 and NOAA NECOP grant no. NA90AA-D-SG691, award MAR31. NURC90 (July 1990) survey data were acquired with support from NOAA National Undersca Research Center grant no. 90-OR-SCU/ROV-RABAIAIS, Texas Institute of Oceanography, Louisiana Universities Marine Consortium and Texas A\&M University at Galveston. GYRE90 (July 1990) survey data were acquired on R/V GYRE Cruise 90G10 supported by Texas A\&M Lniversity Sea Grant Program.

\section{IITERATURF, CITED}

AMbrose, R. B., JR., T. A. WoOL, J. P. CONNOLly', and R. W. SCIIANZ. 1988. WASP4, A IIydrodynamic and Water Quality Model-Model Theory, Lser's Manual, and Programmer's Guide. United States Environmental Protection Agency, Environmental Rescarch Laboratory, Athens, Georgia. EPA/ $600 / 3-87 / 039$.

Ammfrmav. J. W. 1992. Seasonal variation in phosphate turnover in the Mississippi River plume and the inner Gulf Shelf: Rapid summer turnover, p. 69-75. In Nutrient Fnhanced Coastal Ocean Productivity. Publication Number TAML-SG92-109, Sea Grant Program, Texas A\&M Lniversity, Galveston, Texas.

Benner, R., G. Chin-Leo, W. Gardiner, B. Fadie, and J. Cotntr. 1992. The fates and effects of riverine and shelf-derived DOM on Mississippi River plume/Gulf shelf processes, p. 81-94. In Nutrient Enhanced Coastal Occan Productivity. Publication Number TAMU-SG-92-109, Sea Grant Program, Texas A\&M University, Galveston, Texas.

BierMaN, V.J., JR., S. C. I Iinz, W. J. Wisemax, JR., N. N. RABai AIS, AND R. F. TLRNER. 1992. Mass balance modeling of water quality constituents in the Mississippi River plume/inner Gulf shelf region, p. 27-36. In Nutrient Enhanced Coastal Ocean Productivity. Publication Number TAMU-SG-92-109, Sca Grant Program, Texas $\Lambda \& M$ Lniversity, Galveston, Texas.

Bowif, G. L., W. B. Mills, D. B. Porcella, C. L. Camprell, J. R. Paghnkopf, G. I. Rlpp, K. M. Johinson, P. W. II. Chan, AND S. A. Gherivi. 1985. Rates, Constants, and Kinetics Formulations in Surface Water Quality Modeling (Second Fdition). United States Environmental Protection Agency, Environmental Research Laboratory, Athens, Georgia, EPA/600/ 3-85/040.

Crrco, C. F. AND T. Cole. 1993. Three-dimensional cutrophication model of Chesapeake Bay. Journal of Envirommental Engineering 119:1006-1025.

CochravF, J. D. AND F. J. Kei.ly. 1986. I ow-frequency circulation on the Texas-I ouisiana continental shelf. Journal of Geophysical Research 91:10,645-10,659.

DINAFI., S. P. AND W. J. WISEMAN, JR. 1986. Freshwater on the Louisiana and Texas shelf. Continental Shelf Research 6:765-784.

DiToro, D. M. AND W. F. MAIYsitk, JR. 1979. Phosphorus recycle and chlorophyll in the Great I akes. Journal of Great Lakes Research 5:233-245.

DíToro, D. M., N. A. Ihomas, C. k. Herdevdorf, R. P. WriFIE.L, AND J. P. CoNNoLLY. 1987. A post-audit of a Lake Erie eutrophication model. Joumal of Great Lakes Research 13:801825.

DORICH, Q., A. BODE, AND R. R. TwII.Fy. 1992a. Nitrogen uptake and regeneration in surface waters of the I,ouisiana continental shelf influenced by the Mississippi River, p. 52-56. In Nutrient Enhanced Coastal Ocean Productivity. Publication 
Number TAMU-SG-92-109, Sea Grant Program, Texas A\&M University, Galveston, Texas.

Dortch, Q., C. Pham, N. N. Rabalais, and R. E. Tur.irg. 1992b. Respiration rates in bottom waters of the Louisiana shelf, $p$. 140-144. In Nutrient Enhanced Coastal Ocean Productivity. Publication Number TAMU-SG-92-109, Sea Grant Program, Texas A\&M Lniversity, Galveston, Texas.

Fahinenstiel, G. L., M. H. Marcovti\%, M. J. McCormick, D. G. RFInA.jE, S. E. L OHRFi\%, H. J. CaRRICK, AND M. J. DAGG. 1992. High growth and microzooplankton-grazing loss rates for phytoplankton populations from the Mississippi River plume region, p. 111-116. In Nutrient Enhanced Coastal Ocean Productivity. Publication Number TAML-SG-92-109, Sea Grant Program, Texas A\&M University, Galveston, Texas.

FashaM, M. J. R., II. W. Duckiow, AND S. M. MciKflute. 1990. $\Lambda$ nitrogen-based model of plankton dynamics in the oceanic mixed layer. Journal of Marine Research 48:591-639.

HENDEF, J. C. 1994. Data management for the nutrient enhanced coastal ocean productivity program. Fstuaries 17:900903.

Hoffmax, E. E. 1988. Plankton dynamics on the outer southeastern U.S. continental shelf. Part III: A coupled physicalbiological model. Journal of Manine Research 46:919-946.

JORGFNSEN, S. E., S. N. NIFISEN, AND L. A. JORGENSEN. 1991. Handbook of Ecological Parameters and Ecotoxicology. Elsevier, New York.

Justic, D., N. N. Rabalais, R. F. Turviek, and W. J. Wisfichn, JR. 1993. Seasonal coupling between riverborne nutrients, net productivity, and hypoxia. Marine Pollution Bulletin 26:184189.

Krimp, W. M., P. A. SAmpoy, J. Garber, J. Tlitile, and W. R. Bonnton. 1992. Seasonal depletion of oxygen from bottom waters of Chesapeake Bay: Roles of benthic and planktonir respiration and physical exchange processes. Marine Ecology Progress Series 85:137-152.

KRF.MfR, J. N. AND S. W. Nixon. 1978. A Coastal Marine Ecosystem-Simulation and Analysis. Ecological Studies, Volume 24. Springer-Verlag, Berlin.

Lohrenz, S. E., D. G. Rediljf, G. L. Fainfenstifl, aNo G. $\Lambda$. IANG. 1992. Regulation and distribution of primary production in the northern Gulf of Mexico, p. 95-104. In Nutrient Enhanced Coastal Ocean Productivity. Publication Number TAML-SG-92-109, Sea Grant Program. Texas A\&:M University, Galveston, Texas.

LOPEZ-VENFRoNi, D. A.Ni L. A. CIFLENTES. 1992. Dissolved organic nitrogen distribution and transport in the continental shelf of the northwest Gulf of Mexico, p. 57-68. In Nutritnt Enhanced Coastal Ocean Productivity. Publication Number TAMU-SG-92-109. Sea Grant Program, Texas A\&M University, Galveston, Texas.

O'CONOR, D. J. 1981. Modeling of eutrophication in estuaries, p. 183-223. In B. J. Nicilson and I. E. Cronin (eds.), Estuaries and Nutrients. The Humana Press, Clifton, New Jersey.

O'Connor, D. J., J. L. Mavcini, aNd J. R. Guirriero. 1981. Evaluation of factors influencing the temporal variation of dissolved oxygen in the New York Bight. Report to MESA New York Bight Project, National Oceanic and Atmospheric Administration.

Officer, C. B., R. B. Bigos, J. L. Taft, L. E. Cronin, M. A. Ty.fr,
AND W. R. BonTON. 1984. Chesapeake Bay anoxia: Origin, development and significance. Science 223:22-27.

Rabai.ais, N. N., R. F. TIIRNFr, W. J. Wisemai, JR., NiD D. F. BOESCH. 1991. A brief summary of hypoxia on the northern Gulf of Mexico continental shelf: 1985-1988, p. 35-47. In R. V. Tyson and T. II. Pearson (eds.), Modern and Ancient Continental Shelf Anoxia. Geological Society Special Publication No. 58. London.

Rabilais, N. N., R. E. TLRNer, and W. J. Wisfmax, JR. 1992. Distribution and characteristics of hypoxia on the Louisiana shelf in 1990 and 1991, p. 15-20. In Nutrient Enhanced Coastal Ocean Productivity. Publication Number TAML-SG-92-109, Sea Grant Program, Texas A\&M University, Galveston, Texas.

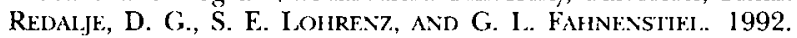
The relationship between primary production and the export of POM from the photic zone in the Mississippi River Plume and inner Gulf of Mexico shelf regions, p. 105-110. In Nutrient F.nhanced Coastal Ocean Productivity. Publication Number TAML-SG-92-109, Sea Grant Progran, Texas A\&.M University, Galveston, Texas.

RODGFR, P. W. AND D. K. SAIISBLRY. 1981. Water quality modeling of Iake Michigan and consideration of the anomalous ice cover of 1976-1977. Joumal of Great Lakes Research 7:467180.

Rowe, G. T., G. S. Bolnd, ANd W. C. Phofi. 1992. Benthic community oxygen demand and nutrient regeneration in sediments near the Mississippi River Plume, p. 136-139. In Nutrient Enhanced Coastal Ocean Productivity. Publication Number 'TAML-SG-92-109, Sea Grant Program, Texas A\&M University, Galveston, Texas.

STANi.fY, D. W. AND S. W. NixoN. 1992. Stratification and bottom-water hypoxia in the Pamlico River Lstuary. Estuaries 15: 270-281.

SIODDARD, A. AND J. J. WAISH. 1988. Modeling oxygen depletion in the New York Bight: The water quality impact of a potential increase of waste inputs, p. 91-102. In D. A. Wolfe and T. P. O'Connor (eds.), Oceanic Processes in Marine Pollution, Volume 5- Lrban Wastes in Coastal Marine Environments. Krieger, Malabar, Florida.

SWANSON, R. I. AND C. J. SINdERMaNix (EdS.). 1979. Oxygen Depletion and Associated Benthic Mortalities in .New York Bight, 1976. NOAA Professional Paper 11, National Oceanic and Atmospheric Administration, Rockville, Maryland.

THomaxi, R. V. AND J. A. Mufli fr. 1987. Principles of Surface Water Quality Modeling and Control. Harper and Row Publishers, New York.

Turier, R. E., W. W. Schrofder, and W. J. Wiseman, JR. 1987. The role of stratification in the deoxygenation of Mobile Bay and adjacent shelf bottom waters. Estuaries 10:13-19.

Tlrner, R. E. ANd N. N. Rabalais. 1991. Changes in Mississippi River water quality this century-Implications for coastal food webs. Bio Srience 41:140-147.

Unitrid States Geological. Survey. 1991. Water Resources Data for Iouisiana, Water Year 1990. Water Data Report IA90-1. United States Geological Survey, Baton Rouge, Louisiana.

Wisfman, W. J., JR., S. P. MterRay, J. M. BANe, aNd M. W. Tlbmax. 1982. Temperature and salinity variability within the Louisiana Bight. Contributions in Marine Science 25:109-120.

Received for consideration, June 9, 1993 Accepled for prublication, April 16, 1994 